\title{
Índice de sustentabilidade empresarial (ISE): uma análise do setor bancário brasileiro listado na B3
}

\section{Eduardo Cezar Teixeira1, Raphael Martini ${ }^{2}$, Diones Kleinibing Bugalho ${ }^{2}$,* e Francieli Morlin ${ }^{3}$}

\begin{abstract}
${ }^{1}$ Universidade Comunitária da Região de Chapecó - Unochapecó. Curso de Graduação em Ciências Contábeis. Servidão Anjo da Guarda, 295-D. Bairro Efapi. Chapecó-SC, Brasil (CEP 89809-900).

${ }^{2}$ Universidade Comunitária da Região de Chapecó - Unochapecó. Mestrado em Ciências Contábeis e Administração. Servidão Anjo da Guarda, 295-D. Bairro Efapi. Chapecó-SC, Brasil (CEP 89809-900).*E-mail: diones.bugalho@unochapeco.edu.br. ${ }^{3}$ Universidade Federal de Santa Catarina. Mestrado em Contabilidade. Rua Engenheiro Agronômico Andrei Cristian Ferreira, s/n. Bairro Trindade, Florianópolis-SC, Brasil (CEP 88040-900).
\end{abstract}

Resumo. O objetivo desta pesquisa é comparar o desempenho, através de indicadores contábil-financeiros, entre bancos da B3 listados e não listados na carteira do índice de sustentabilidade empresarial que disponibilizaram seus demonstrativos contábeis do período de 2016 a 2018 em endereços eletrônicos. A pesquisa classifica-se como descritiva do tipo documental e uma abordagem quantitativa. Os indicadores econômicos financeiros utilizados nessa pesquisa foram a independência financeira, o retorno sobre o patrimônio líquido, a margem líquida, a margem financeira e a lucratividade dos ativos. As evidências encontradas indicam não existir sinergia suficiente para assegurar que a participação na carteira de sustentabilidade interfere nos indicadores econômico-financeiros das instituições financeiras estudadas. Uma vez que, com os resultados obtidos não foi possível afirmar que a participação na carteira do índice de sustentabilidade empresarial representa superioridade no desempenho financeiro. Além de que, também foi possível concluir que os bancos não pertencentes à carteira, apresentaram melhores resultados nos indicadores de margem financeira e lucratividade dos ativos.

Palavras-chave: Sustentabilidade; ISE; B3; Contabilidade e finanças.

Abstract. Corporate sustainability index (ISE): An analysis of the Brazilian banking sector listed in B3. The purpose of this research is to compare performance, calculate financial and financial indicators, between B3 banks listed in the corporate sustainability index portfolio and unlisted banks, which make their financial statements for the period 2016 to 2018 available in the free tests. A research is classified as descriptive of the
Recebido

$10 / 04 / 2020$

Aceito

$17 / 10 / 2020$

Disponível on line $18 / 10 / 2020$

Publicado

$31 / 12 / 2020$

Acesso aberto

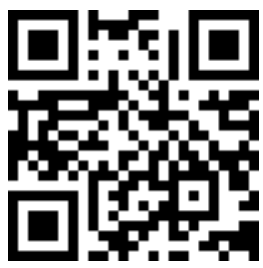

ORCID

(D) 0000-0001-9847-1166

Eduardo Cezar

Teixeira

(D) 0000-0002-6764-4949 Raphael Martini

ISSN 2359-1412/RBGAS-2020-0060/2020/7/17/11/1183

Rev. Bras. Gest. Amb. Sustent.

http://revista.ecogestaobrasil.net 
documentary type and a quantitative approach. The economic and economic indicators used in this research were the financial independence, the return on equity, net margin, financial margin and profitability of assets. As the samples considered do not have enough synergy to ensure that participation in the sustainability portfolio interferes with the economic and financial indicators of the financial institutions studied. Since, with the results obtained, it was not possible to determine the participation in the corporate sustainability index portfolio, which represents superior financial performance. In addition, it was also possible to conclude nonportfolio banks, showing better results in the financial margin and profitability indicators of the assets.

Keywords: Sustainability; ISE; Banking sector; Accounting and finances.

\section{Introdução}

Devido à crescente conscientização da sociedade voltada ao desenvolvimento sustentável, iniciou-se uma tendência mundial por parte dos investidores em aplicar seus recursos em empresas socialmente responsáveis, sustentáveis e rentáveis. Tais investimentos se devem principalmente por acreditar que essas empresas estão mais preparadas para enfrentar riscos econômicos, sociais e ambientais, e, consequentemente, em longo prazo gerar maior retorno ao acionista (Barakat et al., 2016).

A sustentabilidade é entendida como um conjunto de atividades que de uma forma ou outra envolvem as organizações com o meio ambiente, a economia e a sociedade, possibilitando assim a melhoria da imagem e sua reputação, captação de recursos de investimento e maior vantagem competitiva (Guimarães et al., 2017).

Criado em 2005 pela Bolsa de Valores, Mercadorias e Futuros de São Paulo (B3), o Índice de Sustentabilidade Empresarial (ISE) tem como objetivo identificar empresas reconhecidas pelo comprometimento com a responsabilidade social. A carteira do ISE é composta por até 40 empresas, pré-selecionadas anualmente, que estejam entres as 200 ações mais líquidas e que possuam ações negociadas em pelo menos $50 \%$ dos pregões nos últimos doze meses (Guimarães et al., 2018).

Desta forma o ISE está se tornando uma estratégia para as instituições, já que estas não estão preocupadas somente com o lucro ao final de um período, mas também pela visibilidade perante as stakeholders através de participações e iniciativas sustentáveis e da evidenciação que pode representar uma vantagem competitiva no mercado (Rufino et al. 2014).

Romano et al. (2016), afirmam que os índices de sustentabilidade disponibilizam, para diversos agentes econômicos, benchmarking do desempenho financeiro das melhores empresas classificadas em relação à responsabilidade social e ambiental.

Segundo Souza et al. (2017), as instituições financeiras desempenham um papel importante para a economia de um país e consistem no principal canal de intermediação financeira. Devido às características específicas dessa intermediação, o gerenciamento econômico-financeiro de tais instituições apresenta algumas particularidades. 0 desenvolvimento de modelos que contribuem para análise de desempenho e permitem a comparação entre diferentes instituições financeiras é importante para o processo de tomada de decisões, tanto para os agentes internos quanto para aqueles externos a essas instituições. 
Uma metodologia muito utilizada para que se faça a análise do desempenho econômico-financeiro das organizações é a criação de indicadores por meio da análise das demonstrações contábeis. O principal objetivo da análise das demonstrações contábeis é extrair informações que favoreçam a tomada de decisões. A utilização dos indicadores permite que o analista extraia tendências e compare os índices com padrões preestabelecidos. Souza et al. (2017), diz que por meio da análise de indicadores é possível realizar uma comparação padronizada das empresas, uma vez que os indicadores financeiros são desenvolvidos para extrair informações que podem não ser óbvias ao se examinar as demonstrações financeiras.

Neste contexto, a questão a ser respondida com o presente artigo é: Quais as diferenças no desempenho econômico-financeiro do setor bancário pela adoção do índice de sustentabilidade empresarial? E tem por objetivo, verificar as diferenças no desempenho econômico-financeiro do setor bancário pela adoção do índice de sustentabilidade empresarial.

Justifica-se a importância deste artigo em enriquecer o debate atual entre responsabilidade social e desempenho financeiro por meio de análise econômicofinanceira do índice socialmente responsável brasileiro (ISE). Também, procura verificar se a participação de um banco no ISE pode intervir em uma possível melhoria do seu desempenho financeiro. Confirmando-se esta ideia, participar da carteira do ISE poderia ser visto como uma estratégia e ser adotada por diversas empresas. Além disso, Guimarães et al. (2018), sugerem que os bancos estão entre entidades que mais investem em responsabilidade socioambiental, fato provado diante da significativa participação no ISE.

\section{Sustentabilidade empresarial}

A sustentabilidade empresarial pode ser compreendida como um estado econômico em que as demandas colocadas sobre o meio ambiente, as pessoas e o comércio podem ser atendidas sem danificar ou reduzir a capacidade do meio ambiente de prover as gerações futuras (Oliveira et al., 2010).

O conceito de Responsabilidade Social ou Sustentabilidade Empresarial, ao longo do tempo, vem sendo discutido e implantado com frequência às instituições que buscam divulgar à comunidade interna e externa suas ações voltadas à manutenção e ao aumento do bem-estar dos agentes sociais. Conforme Oro et al. (2007), a responsabilidade social pode ser vista como uma forma de unir a empresa com a sociedade local e também com todos os envolvidos por suas atividades, direta ou indiretamente. Ou seja, passa a estabelecer uma relação de ética e transparência, que visa ao desenvolvimento sustentável.

Maia et al. (2017) afirmam que a sustentabilidade é um termo utilizado para ações de atividades realizadas pelos humanos, que não comprometem o futuro das próximas gerações, isto é, a realização de ações sustentáveis sem agredir o meio ambiente, utilizando os métodos naturais de forma inteligente, garantindo um melhor desenvolvimento das gerações futuras, sem agravamento ao aquecimento global, buscando sempre alternativas para a resolução dos efeitos causados.

Para Machado et al. (2012) a responsabilidade social pode ser conceituada como um compromisso da empresa em relação à sociedade, cuja participação das empresas não se limita somente a gerar lucros, empregos e ao pagamento de impostos. Essa é uma forma de gestão definida pela relação ética e transparente que a empresa tem com todos os públicos com os quais ela se relaciona, sendo vista, portanto, como uma forma de accountability do desempenho empresarial, no que tange sua maneira de agir, impactar e de relacionar-se com seus stakeholders. Em outras palavras, a responsabilidade social tem como principal característica a coerência ética nas práticas e relações com seus diversos públicos.

Rev. Bras. Gest. Amb. Sustent., 2020, vol. 7, n. 17, p. 1183-1196. 
Maia et al. (2017) também destaca que a sustentabilidade empresarial abrange três indicadores, sendo eles, ambiental, social e econômico. Estes indicadores têm o propósito de que cada empresa de capital aberto desenvolva programas sustentáveis, visando o respeito ao meio ambiente e o desenvolvimento sustentável da própria sociedade. Estas práticas objetivam também, seu crescimento econômico, sem agredir o meio ambiente e o desenvolvimento da sociedade.

Existe uma ampla literatura nacional e internacional, teórica e empírica, sobre a relação entre investimentos socialmente responsáveis e desempenho financeiro. Segundo Machado et al. (2009), o maior questionamento destes estudos trata-se do quão superior, inferior ou semelhante tais investimentos são, quando comparados aos investimentos convencionais, que por sua vez, não utilizam critérios sociais e ambientais.

Nas palavras de Melo et al. (2012), a preocupação com as posturas socialmente corretas, ambientalmente sustentáveis e economicamente viáveis está cada vez mais presente entre os temas da gestão, ao passo que a sustentabilidade pode ser percebida como um dos temas mais lembrados e propagados na logística. Tudo isso porque, num ambiente em que a informação trafega com grande velocidade nas diversas mídias, 0 impacto tanto positivo quanto negativo para as empresas torna-se disponível a todos, quase que em tempo real.

0 crescimento da sustentabilidade empresarial está diretamente ligado às constantes mudanças observadas no mercado de capitais, em virtude da maior democratização e transparência na circulação de informações. Guimarães et al. (2017) lembram alguns acontecimentos históricos que evidenciaram esse progresso, com destaque para algumas catástrofes como a de Bhopal, na Índia, em 1984, e o acidente nuclear de Chernobyl, em 1986, na Europa. Posteriormente a episódios como esses, foi formulado o relatório de Brundtland (1988), o qual lançava conceitos de sustentabilidade, alterando, assim, algumas práticas de negócios no mundo.

Em 1999, foi criado, nos EUA, o Dow Jones Sustainability Index, Índice de Sustentabilidade Dow Jones (DJSI), primeiro índice a avaliar o desempenho financeiro das empresas líderes em sustentabilidade. No Brasil, com evidente crescimento e conscientização da sociedade voltada à sustentabilidade, a Bolsa de Valores, Mercadorias e Futuros de São Paulo (B3), criou em 2005 o Índice de Sustentabilidade Empresarial (ISE), a quarto do tipo no mundo, sendo que são convidadas a participar da carteira as empresas que detêm as 200 ações mais líquidas na B3. O ISE busca criar um ambiente de investimento compatível com as demandas de desenvolvimento sustentável da sociedade contemporânea e estimular a responsabilidade ética das corporações. Seu desenho metodológico é de responsabilidade do Centro de Estudos em Sustentabilidade (GVCes) da Escola de Administração de Empresas de São Paulo da Fundação Getúlio Vargas (FGVEAESP). A B3 é responsável pelo cálculo e pela gestão técnica do índice.

\section{Desempenho econômico-financeiro}

Para analisar o desempenho de uma empresa em qualquer ramo de atividade são necessários indicadores, que podem ser divididos em econômicos, que analisam o retorno da empresa, e financeiros que analisam a situação financeira e fluxo de caixa.

A conscientização dos clientes em exigir bens com qualidade, a concorrência entre as empresas, a importância dos funcionários para a empresa e o impacto das atividades empresariais na sociedade tem gerado a necessidade das organizações aderirem a modelos de gestão, a fim de produzir informações úteis e relevantes sobre seu desempenho, auxiliando na tomada de decisões por parte dos gestores (Silva et al., 2018).

Karpinski e Kühl (2018) relatam que o desempenho organizacional se refere a um conceito que mede a posição da empresa no mercado e a habilidade da empresa em atender as necessidades de seus stakeholders. Para medir e avaliar a posição da empresa no mercado são necessárias informações que possibilitem gerar indicadores, sendo estes, 
alguns dos instrumentos de mensuração e avaliação do desempenho. Os indicadores de desempenho, por sua vez, representam um poderoso instrumento que dá a empresa condições de realizar esta verificação e avaliação de forma consistente.

Com isso, percebe-se a importância da avaliação de desempenho organizacional. Segundo Bortoluzzi et al. (2011), a análise de desempenho de uma organização é sempre algo passível de muitas discussões e questionamentos sobre quais indicadores utilizar e como consolidá-los. Nessa mesma linha de argumentação, também afirmam que a avaliação patrimonial das empresas tem provocado enormes discussões acadêmicas e profissionais ao longo do tempo. Todos esses fatores têm contribuído para o surgimento de novas abordagens, modelos, ferramentas de Avaliação de Desempenho, para apoiar as empresas na gestão de seus negócios.

Para analisar o desempenho de uma empresa em qualquer ramo de atividade são necessários indicadores. Os indicadores podem ser divididos em econômicos, que analisam o retorno da empresa, e financeiros que analisam a situação financeira e fluxo de caixa (Oliveira et al., 2010).

Assim, Silva et al. (2018) também destacam que os índices financeiros principais, por convenções geradas da administração contábil, são os de liquidez, rentabilidade e endividamento. Os indicadores de desempenho econômico financeiro devem ser considerados como ferramenta aos processos de planejamento estratégico e controle. Complementa ainda que a análise de desempenho organizacional por meio de indicadores possibilita ações para demonstração dos pontos fortes e fracos das empresas.

Silva et al. (2017) definem a análise econômico-financeira como um conjugado de informações, que organizadas, formam um sistema de medida de desempenho. Se, por um lado, a informação for inerente à organização auxilia os gestores na tomada de decisão e no retorno das informações (feedback).

Os Índices de Rentabilidade mensuram o retorno advindo sobre os investimentos em geral, ou seja, analisam a capacidade dos recursos que foram investidos em relação ao lucro que os mesmos proporcionaram. Segundo Marion (2012) Índices de Rentabilidade podem ser subdivididos em Rentabilidade do Ativo, que analisa o percentual do Lucro Líquido referente ao Ativo total Médio, ou seja, mede o poder de ganho da empresa; e Rentabilidade do Empresário, que analisa o percentual do Lucro Líquido referente ao capital investido pelos sócios, ou seja, mede o poder de ganho dos empresários.

Os Indicadores de estrutura de Capitais mostram as linhas de decisões financeiras em termos de obtenção e aplicação de recursos, ou seja, demonstra a análise das fontes de financiamento indicando a relação da dependência da empresa em função dos recursos de terceiros. Os indicadores representativos da estrutura de capitais mais conhecidos são: Endividamento Geral; Participação de Capital de Terceiros; Composição do Endividamento; Grau de Imobilização do Patrimônio Líquido; Imobilização dos Recursos Não Correntes; e Índice de cobertura de juros (Kos et al., 2014).

\section{Metodologia}

A metodologia é caracterizada por meio de uma classificação descritiva do tipo documental e uma abordagem quantitativa, uma vez que procurou analisar o comportamento financeiro de bancos participantes e não participantes da carteira do ISE por meio do cálculo de indicadores contábil-financeiros.

Quanto aos objetivos trata-se de uma pesquisa descritiva, pois busca descrever a influência da participação na carteira do Índice de Sustentabilidade Empresarial (ISE) do setor bancário no desempenho econômico-financeiro. Segundo Michel (2009), a classificação metodológica descritiva se propõe a verificar e explicar problemas, fatos ou fenômenos da vida real, com a precisão possível, observando e fazendo relações, conexões, 
à luz da influência que o ambiente exerce sobre eles. Portanto, os estudos desta natureza procuram definir as características de um fenômeno.

Abaixo, apresenta-se uma descrição de cada indicador contábil-financeiro escolhido, segundo Assaf Neto (2010), e suas respectivas fórmulas na Tabela 1.

Tabela 1. Indicadores contábil-financeiros.

\begin{tabular}{|l|l|}
\hline Indicador & Fórmula \\
\hline Independência Financeira & Patrimônio Líquido/Ativo Total \\
\hline Retorno sobre o Patrimônio Líquido & Lucro Líquido/Patrimônio Líquido \\
\hline Margem Líquida & Lucro Líquido/Receita de Intermediação Financeira \\
\hline Margem Financeira & $\begin{array}{l}\text { Resultado Bruto - Intermediação Financeira/Ativo } \\
\text { Total }\end{array}$ \\
\hline Lucratividade dos Ativos & Receita de Intermediação Financeira/Ativo Total \\
\hline
\end{tabular}

Fonte: Elaborado pelos autores com base em Assaf Neto (2010).

Para o cálculo dos indicadores contábil-financeiros responsáveis por conceder uma representação do comportamento financeiro das instituições em questão, foram coletadas as seguintes variáveis nos demonstrativos financeiros: Ativo, Patrimônio Líquido, Lucro Líquido, Receita de Intermediação Financeira e Resultado Bruto da Intermediação Financeira. Os dados obtidos sobre os indicadores foram analisados através da aplicação de estatísticas descritivas: média, valor máximo, valor mínimo e desvio padrão.

Obedecendo às particularidades dos Relatórios e Demonstrações Contábeis deste segmento, foram selecionados para estudo os seguintes indicadores: Independência Financeira, Retorno sobre o Patrimônio Líquido, Margem Líquida, Margem Financeira e Lucratividade dos Ativos (Assaf Neto, 2010). Apresenta-se a seguir, uma breve definição de cada indicador contábil-financeiro adotado a pesquisa, segundo Assaf Neto (2010):

Independência Financeira: representa o percentual do Patrimônio Líquido em relação ao Ativo Total.

Retorno sobre o Patrimônio Líquido: representa o ganho percentual obtido pelos proprietários em relação aos recursos investidos. Assim, "mede, para cada R\$1 investido, o retorno líquido do acionista".

Margem Líquida: representa o percentual do Lucro Líquido em relação à Receita de Intermediação Financeira dos bancos. Assim, "é formada pelos vários resultados da gestão dos ativos e passivos dos bancos (taxas, prazos, receitas e despesas), permitindo avaliar a função básica de intermediação financeira de um banco".

Margem Financeira: representa a relação entre o resultado bruto da intermediação financeira e o ativo total dos bancos. É o termo utilizado na análise dos bancos e que resulta na diferença entre os juros cobrados pelos créditos concedidos e os juros pagos aos clientes pelos montantes que estes confiam aos bancos.

Lucratividade dos Ativos: representa a relação entre a Receita de Intermediação Financeira e o Ativo Total, ou seja, a porcentagem do total investido responsável por gerar as receitas financeiras dos bancos.

Com relação à abordagem metodológica quantitativa, a pesquisa utilizou o método de quantificação na coleta e também no tratamento dos dados. Pois busca expressar seus resultados por meio dos cálculos estatísticos que foram realizados a partir dos dados 
obtidos. É indicado este modelo de pesquisa quando o objetivo é obter resultados precisos e comprovados, evitando distorções de análises (Michel, 2009).

Para análise dessa pesquisa foram realizados cálculos de correlação com auxílio do Software Excel $®$, individualmente para cada variável da instituição financeira. Para a análise foi utilizado tanto dados primários quanto secundários, já que foram coletadas informações financeiras referentes ao exercício social dos anos de 2016, 2017 e 2018 presentes nas Demonstrações Consolidadas ou, quando não apresentadas, nas Demonstrações Individuais das empresas obtidas no site eletrônico da B3. Por meio de informações extraídas dos demonstrativos foram calculados indicadores contábilfinanceiros para avaliação do desempenho dos bancos.

Quanto aos procedimentos, trata-se de uma pesquisa documental, pois analisa dados que já foram elaborados e apresentados e que estão disponíveis no site da B3. Colauto e Beuren (2003) afirmam que a pesquisa documental é aquela que está baseada em organizar dados que já estão expostos, ou seja, é aquela que se justifica por analisar documentos que já foram descritos.

A amostra da pesquisa ocorreu no período de agosto de 2019 e está composta pelas 22 empresas do segmento bancos pertencentes ao setor financeiro da B3 que disponibilizaram seus demonstrativos necessários em endereços eletrônicos. Além disso, as amostras que foram analisadas são divididas em dois grupos: cinco bancos participantes carteira ISE dos anos de 2016, 2017 e 2018 e dezessete bancos não participantes da carteira conforme apresentado na Tabela 2.

Tabela 2. Amostra da pesquisa.

\begin{tabular}{|c|c|}
\hline Razão social & Nome de Pregão \\
\hline \multicolumn{2}{|l|}{ Bancos pertencentes à carteira do ISE } \\
\hline Bco Bradesco S.A. & Bradesco \\
\hline Bco Brasil S.A. & Brasil \\
\hline Bco Santander (Brasil) S.A. & Santander $\mathrm{Br}$ \\
\hline Itaú Unibanco Holding S.A. & Itauunibanco \\
\hline Itausa Investimentos Itau S.A. & Itausa \\
\hline \multicolumn{2}{|l|}{ Bancos não pertencentes à carteira ISE } \\
\hline Banco Inter S.A. & Banco Inter \\
\hline Banestes S.A. - Bco Est Espirito Santos & Banestes \\
\hline Bco ABC Brasil S.A. & ABC Brasil \\
\hline Bco Alfa de Investimentos S.A. & Alfa Invest \\
\hline Bco Amazonia S.A. & Amazonia \\
\hline Bco BTG Pactual S.A. & BTGP Banco \\
\hline Bco Estado de Sergipe S.A. - Banese & Banese \\
\hline Bco Estado do Rio Grande do Sul S.A. & Banrisul \\
\hline Bco Indusval S.A. & Indusval \\
\hline Bco Mercantil de Investimentos S.A. & Merc Invest \\
\hline Bco Mercantil do Brasil S.A. & Merc Brasil \\
\hline Bco Nordeste do Brasil S.A. & Nord Brasil \\
\hline Bco Pan S.A. & Banco Pan \\
\hline Bco Patagonia S.A. & Patagonia \\
\hline Bco Pine S.A. & Pine \\
\hline BRB Bco de Brasilia S.A. & BRB Banco \\
\hline Parana Bco S.A. & Parana \\
\hline
\end{tabular}


De acordo com Rufino et al. (2014), os bancos precisam adequar seus relatórios financeiros, demonstrações contábeis e documentos de forma geral segundo o Plano Contábil das Instituições do Sistema Financeiro Nacional - Cosif, expedido pelo Banco Central do Brasil.

O segmento escolhido para tal estudo foi bancos, devido sua representatividade sobre a carteira do ISE do ano de 2018. A porcentagem de bancos com relação ao total de empresas participantes do ISE no ano referente foi superior a $16 \%$.

\section{Resultados e discussão}

Foram utilizadas técnicas de estatísticas descritivas para análise dos indicadores contábil-financeiros, sendo elas: média, valor máximo, valor mínimo, e desvio padrão. Também é importante ressaltar que os dados foram avaliados em conformidade com a seguinte concepção: quanto maior, melhor para a entidade.

Índice independência financeira, representa a necessidade de recursos de terceiros para a continuidade de suas atividades.

0 indicador independência financeira apresenta, em todos os dados da pesquisa, valor superior no grupo dos bancos participantes da carteira do ISE. Outro dado a ser ressaltado é que, apesar de não considerável, houve constante crescimento na média dos bancos listados, enquanto que o grupo dos não listados apresenta uma maior variação entre os períodos analisados, bem como uma redução de aproximadamente $20 \%$ do mesmo dado entre os períodos de 2016 e 2017 (Tabela 3).

Tabela 3. Índice de independência financeira entre bancos ISE e não ISE.

\begin{tabular}{|c|c|c|c|c|c|c|}
\hline $\begin{array}{c}\text { Independência } \\
\text { Financeira }\end{array}$ & $\begin{array}{c}\text { Número } \\
\text { de Bancos }\end{array}$ & Ano & Média & $\begin{array}{c}\text { Valor } \\
\text { Máximo }\end{array}$ & $\begin{array}{c}\text { Valor } \\
\text { Mínimo }\end{array}$ & $\begin{array}{c}\text { Desvio } \\
\text { Padrão }\end{array}$ \\
\hline \multirow{4}{*}{$\begin{array}{c}\text { Bancos Participantes da } \\
\text { Carteira ISE }\end{array}$} & \multirow{4}{*}{5} & 2016 & 0,2483 & 0,8564 & 0,0649 & 0,3408 \\
\cline { 3 - 7 } & & 2017 & 0,2522 & 0,8544 & 0,0748 & 0,3374 \\
\cline { 3 - 7 } & & 2018 & 0,2542 & 0,8772 & 0,0749 & 0,3488 \\
\cline { 3 - 7 } & Total & 0,2516 & 0,8627 & 0,0715 & 0,3423 \\
\hline \multirow{3}{*}{$\begin{array}{c}\text { Bancos Não Participantes } \\
\text { da Carteira ISE }\end{array}$} & \multirow{2}{*}{17} & 2016 & 0,1633 & 0,9136 & 0,0491 & 0,1970 \\
\cline { 3 - 7 } & 2017 & 0,1392 & 0,5439 & 0,0607 & 0,1119 \\
\cline { 3 - 7 } & 2018 & 0,1483 & 0,7153 & 0,0527 & 0,1534 \\
\cline { 3 - 7 } & & Total & 0,1503 & 0,7242 & 0,0541 & 0,1541 \\
\hline
\end{tabular}

Com isso, é possível afirmar na análise da comparação do índice independência financeira, que os bancos participantes da carteira do ISE, apresentam considerável supremacia sobre os não participantes, uma vez que, obtiveram maiores resultados em todos os dados da pesquisa. Isso significa que o grupo dos bancos que compõem a carteira do ISE, são menos dependentes de recursos de terceiros para sua continuidade, enquanto os bancos não listados necessitam recorrer mais a terceiros para a ininterrupção de suas atividades.

Para toda instituição, seja ela aberta ou não, a geração de valor através da sua atividade é um objetivo principal e unânime para continuidade e eventual êxito em seu segmento de atuação. Porém, tão importante quanto à geração de lucro líquido é a 
rentabilidade apresentada pelo empreendimento. Neste sentido, o retorno sobre 0 patrimônio líquido é um indicador que demonstra a capacidade da instituição em gerar valor para seu acionista ao longo do tempo.

Com relação à comparação do retorno sobre o patrimônio líquido, é possível observar que os bancos listados na carteira do ISE possuem resultados superiores comparativamente aos bancos não participantes, nas estatísticas de média e valor mínimo durante os três anos em análise. Os bancos não listados se destacam pela superioridade no valor máximo e desvio padrão em todo o período da pesquisa, em relação aos bancos listados na carteira. Com base na média, podemos afirmar que bancos participantes da carteira ISE apresentam um ganho superior em comparação aos recursos próprios investidos (Tabela 4).

Tabela 4. Retorno sobre patrimônio líquido bancos ISE e não ISE.

\begin{tabular}{|c|c|c|c|c|c|c|}
\hline $\begin{array}{c}\text { Retorno sobre o } \\
\text { Patrimônio Líquido }\end{array}$ & $\begin{array}{c}\text { Número } \\
\text { de Bancos }\end{array}$ & Ano & Média & $\begin{array}{c}\text { Valor } \\
\text { Máximo }\end{array}$ & $\begin{array}{c}\text { Valor } \\
\text { Mínimo }\end{array}$ & $\begin{array}{c}\text { Desvio } \\
\text { Padrão }\end{array}$ \\
\hline \multirow{4}{*}{$\begin{array}{c}\text { Bancos Participantes da } \\
\text { Carteira ISE }\end{array}$} & \multirow{4}{*}{5} & 2016 & 0,1372 & 0,1706 & 0,0880 & 0,0414 \\
\cline { 3 - 7 } & & 2017 & 0,1369 & 0,1609 & 0,1049 & 0,0231 \\
\cline { 3 - 7 } & & 2018 & 0,1512 & 0,1704 & 0,1343 & 0,0165 \\
\cline { 3 - 7 } & Total & 0,1418 & 0,1673 & 0,1091 & 0,0270 \\
\hline \multirow{4}{*}{$\begin{array}{c}\text { Bancos Não Participantes } \\
\text { da Carteira ISE }\end{array}$} & 2016 & 0,0974 & 0,3598 & $-0,2317$ & 0,1321 \\
\cline { 3 - 7 } & 17 & 2017 & 0,0411 & 0,2757 & $-0,7246$ & 0,2411 \\
\cline { 3 - 7 } & & 2018 & 0,0481 & 0,1815 & $-0,6477$ & 0,1889 \\
\cline { 3 - 7 } & & Total & 0,0622 & 0,2624 & $-0,5347$ & 0,1874 \\
\hline
\end{tabular}

Margem líquida é o indicador financeiro que evidencia o percentual (multiplicado por 100) de lucro com relação às receitas que uma determinada instituição apresentou no seu demonstrativo de resultados, seja ele trimestral ou consolidado anual. Portanto, entende-se que este, indica ao acionista a porcentagem de cada $\mathrm{R} \$ 1,00$ que restou após a dedução de todos os impostos e despesas provenientes da atividade, e com isso, o investidor tem a oportunidade de explorar a viabilidade do investimento em determinada empresa.

É possível observar na Tabela 5 que os bancos não participantes da carteira do ISE demonstram valores superiores nas estatísticas, valor máximo e também desvio padrão. Já os bancos participantes da carteira apresentam superioridade em valor mínimo nos três anos da pesquisa e média, nos exercícios de 2017 e 2018. Vale ressaltar o constante crescimento da média de margem líquida dos bancos listados na carteira do ISE, durante o tempo em que os bancos não listados apresentam uma considerável variação entre o mesmo dado estatístico. É possível concluir, com base na média total, que os bancos participantes de carteira ISE apresentam uma margem líquida 50\% superior quando comparado aos bancos não pertencentes à carteira (Tabela 5). 
Tabela 5. Margem líquida entre bancos ISE e não ISE

\begin{tabular}{|c|c|c|c|c|c|c|}
\hline Margem Líquida & $\begin{array}{c}\text { Número } \\
\text { de Bancos }\end{array}$ & Ano & Média & $\begin{array}{l}\text { Valor } \\
\text { Máximo }\end{array}$ & $\begin{array}{l}\text { Valor } \\
\text { Mínimo }\end{array}$ & $\begin{array}{l}\text { Desvio } \\
\text { Padrão }\end{array}$ \\
\hline \multirow{4}{*}{$\begin{array}{c}\text { Bancos Participantes da } \\
\text { Carteira ISE }\end{array}$} & \multirow{4}{*}{5} & 2016 & 0,0955 & 0,1258 & 0,0491 & 0,0515 \\
\hline & & 2017 & 0,1231 & 0,1553 & 0,0835 & 0,0607 \\
\hline & & 2018 & 0,1628 & 0,1553 & 0,1255 & 0,0778 \\
\hline & & Total & 0,1271 & 0,1455 & 0,0860 & 0,0633 \\
\hline \multirow{4}{*}{$\begin{array}{c}\text { Bancos Não Participantes } \\
\text { da Carteira ISE }\end{array}$} & \multirow{4}{*}{17} & 2016 & 0,1048 & 0,4166 & $-0,2224$ & 0,1566 \\
\hline & & 2017 & 0,0059 & 0,3006 & $-0,6953$ & 0,2853 \\
\hline & & 2018 & 0,0707 & 0,2820 & $-0,5725$ & 0,1884 \\
\hline & & Total & 0,0605 & 0,3331 & $-0,4967$ & 0,2101 \\
\hline
\end{tabular}

Tal indicador tem associação direta com a rentabilidade da atividade, uma vez que aponta quanto de dinheiro restou para a instituição após todas as deduções, e consequentemente quanto de dividendos a empresa poderá distribuir. Portanto, podemos afirmar que os bancos participantes da carteira do ISE, em sua média, apresentam maior retorno a seus acionistas, quando comparado aos bancos não participantes da mesma carteira.

A margem financeira é definida como a razão entre o resultado de intermediação financeira pelo total do ativo, ou seja, a diferença entre as receitas de intermediação (sobre o total do ativo) e as despesas de intermediação (sobre o total do ativo).

0 indicador margem financeira, obtido pela divisão do resultado bruto da intermediação financeira pelo ativo total, apresenta melhor resultado ao grupo dos bancos não participantes da carteira ISE por meio da análise da média, valor máximo e desvio padrão, durante os três períodos de pesquisa, enquanto os bancos participantes demonstram superioridade somente do valor mínimo. Podemos afirmar, com base na média, que os bancos não pertencentes à carteira do ISE possuem uma margem financeira superior aos pertencentes, uma vez que apresentou superioridade constante nos três exercícios utilizados no estudo (Tabela 4).

Tabela 6. Margem financeira entre bancos ISE e não ISE.

\begin{tabular}{|c|c|c|c|c|c|c|}
\hline Margem Líquida & $\begin{array}{c}\text { Número } \\
\text { de Bancos }\end{array}$ & Ano & Média & $\begin{array}{c}\text { Valor } \\
\text { Máximo }\end{array}$ & $\begin{array}{l}\text { Valor } \\
\text { Mínimo }\end{array}$ & $\begin{array}{l}\text { Desvio } \\
\text { Padrão }\end{array}$ \\
\hline \multirow{4}{*}{$\begin{array}{c}\text { Bancos Participantes da } \\
\text { Carteira ISE }\end{array}$} & \multirow{4}{*}{5} & 2016 & 0,0475 & 0,0603 & 0,0223 & 0,0262 \\
\hline & & 2017 & 0,0444 & 0,0541 & 0,0232 & 0,0234 \\
\hline & & 2018 & 0,0420 & 0,0579 & 0,0273 & 0,0218 \\
\hline & & Total & 0,0446 & 0,0574 & 0,0243 & 0,0238 \\
\hline \multirow{4}{*}{$\begin{array}{c}\text { Bancos Não Participantes } \\
\text { da Carteira ISE }\end{array}$} & \multirow{4}{*}{17} & 2016 & 0,0611 & 0,1566 & $-0,0245$ & 0,0490 \\
\hline & & 2017 & 0,0627 & 0,1732 & $-0,0519$ & 0,0597 \\
\hline & & 2018 & 0,0550 & 0,1593 & $-0,0734$ & 0,0570 \\
\hline & & Total & 0,0596 & 0,1630 & $-0,0499$ & 0,0552 \\
\hline
\end{tabular}


Isso significa que, o grupo dos bancos não participantes da carteira do ISE, possui margem superior entre os juros cobrados pelos créditos concedidos e os juros pagos aos clientes pelos montantes que estes confiam aos bancos, quando comparado aos bancos participantes da mesma carteira.

Lucratividade dos ativos é o índice que evidencia o ganho que a empresa consegue gerar sobre o trabalho que desenvolve, e com isso, quanto maior esse indicador, melhor será a saúde financeira da empresa.

Em análise aos dados do indicador lucratividade dos ativos houve características semelhantes à margem financeira, uma vez que os bancos não pertencentes à carteira do ISE apresentam superioridade nas estatísticas, média, valor máximo e desvio padrão. Os bancos pertencentes da carteira predominam no quesito valor mínimo. Outro ponto a se destacar é a redução constante em praticamente todos os dados estatísticos, que se deve ao crescimento do ativo, não acompanhado na mesma proporção pela receita de intermediação financeira (Tabela 7).

Tabela 7. Lucratividade dos ativos entre bancos ISE e não ISE.

\begin{tabular}{|c|c|c|c|c|c|c|}
\hline Margem Líquida & $\begin{array}{c}\text { Número } \\
\text { de Bancos }\end{array}$ & Ano & Média & $\begin{array}{c}\text { Valor } \\
\text { Máximo }\end{array}$ & $\begin{array}{c}\text { Valor } \\
\text { Mínimo }\end{array}$ & $\begin{array}{c}\text { Desvio } \\
\text { Padrão }\end{array}$ \\
\hline \multirow{3}{*}{$\begin{array}{c}\text { Bancos Participantes da } \\
\text { Carteira ISE }\end{array}$} & \multirow{3}{*}{5} & 2016 & 0,1287 & 0,1367 & 0,1216 & 0,0578 \\
\cline { 3 - 7 } & & 2017 & 0,1090 & 0,1125 & 0,1041 & 0,0488 \\
\cline { 3 - 7 } & & 2018 & 0,0886 & 0,0974 & 0,0846 & 0,0399 \\
\cline { 3 - 7 } & Total & 0,1088 & 0,1155 & 0,1034 & 0,0489 \\
\hline \multirow{2}{*}{$\begin{array}{c}\text { Bancos Não Participantes } \\
\text { da Carteira ISE }\end{array}$} & \multirow{2}{*}{17} & 2016 & 0,1550 & 0,3002 & 0,0789 & 0,0603 \\
\cline { 3 - 7 } & 2017 & 0,1436 & 0,3042 & 0,0755 & 0,0665 \\
\cline { 3 - 7 } & 2018 & 0,1197 & 0,2570 & 0,0657 & 0,0608 \\
\cline { 3 - 7 } & & Total & 0,1395 & 0,2871 & 0,0734 & 0,0625 \\
\hline
\end{tabular}

É possível concluir que os bancos não pertencentes à carteira do ISE, apresentam maior eficiência em produzir lucro por meio de suas atividades. Com isso, torna-se mais atrativo aos olhos de investidores, uma vez que o índice lucratividade dos ativos é um dos principais pontos de análise de eventuais acionistas.

\section{Considerações finais}

O estudo parte da premissa que empresas, no momento em que desenvolvem práticas de sustentabilidade, encontram-se mais preparadas para enfrentarem os imprevistos do ambiente empresarial, no médio e longo prazo. Desse modo, o presente trabalho objetivou apurar a supremacia dos indicadores econômico-financeiros dos bancos considerados sustentáveis, de acordo com a definição do ISE da B3, na comparação com os demais bancos não sustentáveis. Foram analisados os indicadores de vinte e dois bancos ao longo de três anos, cinco bancos sustentáveis e dezessete bancos não sustentáveis.

As instituições financeiras têm como propósito o aumento da riqueza dos acionistas. Sobre os índices básicos de rentabilidade: independência financeira, retorno sobre patrimônio líquido e margem líquida, verificou-se, em linhas gerais, a supremacia dos dados dos bancos participantes da carteira do ISE. Também, pôde-se constatar maior 
estabilidade dos índices nos bancos sustentáveis, enquanto os bancos não pertencentes da carteira do ISE apresentaram constante variação dos dados, com destaque para o retorno sobre o patrimônio líquido e para a margem líquida.

Em relação aos demais índices de rentabilidade e lucratividade, os bancos não participantes da carteira do ISE, em termos gerais, manifestam melhores índices de margem financeira e lucratividade dos ativos. Apesar de apresentarem dados superiores aos bancos listados na carteira do Índice de Sustentabilidade Empresarial, nota-se uma oscilação estável com constante declinação no indicador de lucratividade dos ativos, fato que vem aproximando os dados ano após ano.

Contudo, é possível concluir a não existência de sinergia suficiente para assegurar precisamente que a participação na carteira de sustentabilidade interfere nos indicadores econômico-financeiros dos bancos analisados.

Mesmo sem poder afirmar que o desenvolvimento de práticas sustentáveis impacta diretamente nos indicadores econômico-financeiros dos bancos, nos últimos anos, o Îndice de Sustentabilidade Empresarial desempenhou um papel essencial para atrair o tema sustentabilidade para dentro das organizações.

Por fim, é fundamental mencionar que a exploração deste artigo limitou a estudar os indicadores econômico-financeiros das instituições financeiras, desconsiderando demais pontos com poder de interferência, como dentre outros: política operacional desenvolvida pela instituição; tempo de atuação; qualidade e forma de conduzir suas operações; alteração na política monetária do governo; eventuais crises financeiras ou reflexos da economia.

Sugere-se assim, que outros estudos sejam realizados com o intuito de analisar a variação dos índices econômico-financeiros das empresas do setor bancário no âmbito nacional. Também se recomenda uma pesquisa com sua base fundamentada no ponto de vista populacional a respeito da utilização e substituição de bancos de esfera pública e privada por cooperativas de crédito, elencando os pontos que interferem na decisão para migrar ou escolher uma cooperativa de crédito como instituição financeira.

\section{Conflito de interesses}

Os autores declaram não haver conflito de interesses.

\section{Referências}

Assaf Neto, A. Estrutura e análise de balanços: um enfoque econômico-financeiro. Parte V - Análise de bancos. 9. ed. São Paulo: Atlas, 2010.

Barakat, S. R.; Sanches, M. V.; MacLennan, M. L. F.; Polo, E.; Oliveira Júnior, M. M. Associação entre desempenho econômico e índice de sustentabilidade empresarial da Bolsa de Valores de São Paulo. Gestão \& Regionalidade, v. 32, n. 95, p. 127-142, 2016. https://doi.org/10.13037/gr.vol32n95.3254

Bortoluzzi, S. C.; Ensslin, S. R.; Lyrio, M. V. L.; Ensslin, L. Avaliação de desempenho econômico-financeiro: uma proposta de integração de indicadores contábeis tradicionais por meio da metodologia Multicritério de Apoio à Decisão Construtivista (MCDA-C). Revista Alcance, v. 18, n. 2, p. 200-218, 2011.

Brundtland, G. H. Il futuro di noi tutti. Rapporto della Commissione Mondiale per l'Ambiente e lo Sviluppo. Milan, Italy: Bompiani, 1988.

Colauto, R. D.; Beuren, I. M. Coleta, análise e interpretação dos dados. In: Beuren, I. M. (Org.). Como elaborar trabalhos monográficos em contabilidade: teoria e prática. São Paulo: Atlas, 2003. p. 117-144, 
Guimarães, E. F.; Rover, S.; Ferreira, D. D. M. A participação no Índice de Sustentabilidade Empresarial (ISE): uma comparação do desempenho financeiro de bancos participantes e não participantes da carteira. Enfoque Reflexão Contábil, v. 37, n. 1, p. 147-164, 2018.

Guimarães, T. M.; Peixoto, F. M.; Carvalho, L. Sustentabilidade empresarial e governança corporativa: uma análise da relação do ISE da B3 com a compensação dos gestores de empresas brasileiras. Revista de Educação e Pesquisa em Contabilidade, v. 11, n. 2, p. 134-149, 2017. https://doi.org/10.17524/repec.v11i2.1418

Karpinski, J.; Kühl, M. R. As 8 empresas de melhor desempenho econômico e financeiro do Brasil nos anos de 2014 a 2016. Revista Capital Científico - Eletrônica, v. 16, n. 4, p. 43-56, 2018.

Kos, S. R.; Espejo, M. M. D. S. B.; Raifur, L. O conteúdo informacional do Relatório da Administração e o desempenho das empresas brasileiras do Ibovespa. Revista Universo Contábil, v. 10, n. 2, p. 43-62, 2014. https://doi.org/10.4270/ruc.2014211

Machado, M. A. V.; Macedo, M. A. S.; Machado, M. R.; Siqueira, J. R. M. Análise da relação entre investimentos socioambientais e a inclusão de empresas no índice de sustentabilidade empresarial (ISE) da BM\&FBOVESPA. Revista de Ciências da Administração, $\quad$ v. 14, $\quad$ n. 32, $\quad$ p.141-156, 2012. https://doi.org/10.5007/21758077.2012v14n32p141

Machado, M. R.; Machado, M. A. V.; Corrar, L. J. Desempenho do Índice de Sustentabilidade Empresarial (ISE) da Bolsa de Valores de São Paulo. Revista Universo Contábil, v. 5, n. 2, p. 24-38, 2009.

Maia, V. M.; Carvalho, F. P.; Klotzle, M. C.; Pinto, A. C. F.; Motta, L. F. J. Fazer parte do Índice de Sustentabilidade Empresarial (ISE) implica em maior rentabilidade? Revista de Finanças Aplicadas, v. 8, n. 1, p. 1-22, 2017.

Marion, J. C. Análise das demonstrações contábeis: contabilidade empresarial. São Paulo: Atlas, 2012.

Melo, R. A.; Manhães, J. V. P.; Macedo, M. A. S. Desempenho do Índice de Sustentabilidade Empresarial (ISE) da Bolsa de Valores de São Paulo sob a ótica do Índice de Sharpe. Revista Economia \& Gestão, v. 12, n. 28, p. 75-104, 2012. https://doi.org/10.5752/ P.1984-6606.2012v12n28p75

Michel, M. H. Metodologia e pesquisa científica em Ciências Sociais. 2. ed. São Paulo: Atlas, 2009.

Oliveira, A. A.; Silva, A. R.; Zuccari, S. M. P. A análise das demonstrações contábeis e sua importância para evidenciar a situação econômica e financeira das organizações. Revista Eletrônica Gestão e Negócios, v. 1, n. 1, p. 1-13, 2010.

Oro, I. M.; Renner, S.; Braun, M. Informações de natureza socioambiental: análise dos balanços sociais das empresas integrantes do Índice de Sustentabilidade Empresarial da BM\&FBovespa. Revista de Administração da UFSM, v. 6, n. Edição Especial, p. 879-893, 2013.

Romano, P. R.; Ermel, M. D. A.; Mól, A. L. R. Características das empresas brasileiras pertencentes ao Índice de Sustentabilidade Empresarial (ISE) da BM\&FBOVESPA no período de 2010 a 2013 e seu retorno anormal. Revista Universo Contábil, v. 2, n. 2, p. 620, 2016. https://doi.org/10.4270/ruc.2016211

Rufino, M. A.; Mazer, L. P.; Machado, M. R.; Cavalcante, P. R. N. Sustentabilidade e performance dos indicadores de rentabilidade e lucratividade da BM\&FBovespa. Revista Ambiente Contábil, v.6, n. 1, p. 1-18, 2014. 
Silva, A.; Floriani, R.; Hein, N. Influência do desempenho econômico financeiro nas inovações tecnológicas de empresas brasileiras de capital aberto da construção civil. Revista de Administração da UFSM, v. 11, n. 4, p. 939-954, 2018.

Silva, L. F.; Lucena, W. G. L.; Paulo, E. Uma análise do desempenho econômico e financeiro das IPOs no Brasil. Revista Capital Científico - Eletrônica, v. 15, n. 1, p. 1-17, 2017.

Souza, J. A.; Mendonça, D. J.; Benedicto, G. C.; Carvalho, F. M. Aplicação da análise fatorial para identificação dos principais indicadores de desempenho econômico-financeiro em instituições financeiras bancárias. Revista Catarinense da Ciência Contábil, v. 16, n. 47, p. 26-41, 2017. https://doi.org/10.16930/2237-7662/rccc.v16n47p26-41

Informação da Licença: Este é um artigo Open Access distribuído sob os termos da Licença Creative Commons Attribution, que permite uso irrestrito, distribuição e reprodução em qualquer meio, desde que a obra original seja devidamente citada. 